\title{
Solassist Virtual: um Sistema Imersivo aplicado como Tecnologia Assistiva
}

\section{Solassist Virtual: An Immersive System Applied How Assistive Technology}

\section{Resumo:}

A inclusão das pessoas com deficiência no mercado de trabalho pode ser um diferencial na qualidade de vida desses indivíduos, sendo que a participação de forma igualitária em sociedade, respeitando os direitos e obrigações ainda é um desafio. Este artigo objetiva apresentar e avaliar os benefícios de um sistema imersivo focando na preparação e desenvolvimento das pessoas com deficiência intelectual para inclusão no mercado de trabalho. O Projeto Solassist Virtual busca através das experiências que envolvem Tecnologias Assistivas ajudar nos processos de inclusão de pessoas com deficiência nas organizações produtivas. O Projeto também se baseia na teoria sócio histórica proposta por Vygotsky. A metodologia utilizada foi uma pesquisa qualitativa com estudo de caso e os resultados demonstraram a viabilidade da utilização de um sistema baseado nos conceitos de Ambiente Imersivos na preparação de pessoas com deficiência intelectual para o ambiente laboral.

Palavras-chave: Tecnologia. Aprendizagem. Pessoas com deficiência. Sistema Imersivo.

\begin{abstract}
:
The inclusion of persons with disabilities in the labor market can be a difference in the quality of life of individuals, with the participation equally in society, respecting the rights and obligations is still a challenge. This article presents and evaluate the benefits of an immersive system focusing on the preparation and development of people with intellectual disabilities for inclusion in the labor market. The Virtual Solassist Project seeks through experiments involving Assistive Technologies help us inclusion processes of people with disabilities in productive organizations. Project is also based in the historic socio theory proposed by Vygotsky. The methodology used was a qualitative research with case study and the results demonstrated the feasibility of using a system based on the concepts of Immersive Environment in the preparation of people with intellectual disabilities to the work environment.

Keywords: Technology. Learning. People with disabilities.
\end{abstract} Immersive Sistem.

PIOVESAN, Sandra Dutra; WAGNER, Rosana; MEDINA, Roseclea Duarte; PASSERINO, Liliana Maria. Solassist Virtual: um Sistema Imersivo aplicado como Tecnologia Assistiva. Informática na Educação: teoria e prática, Porto Alegre, v. 18 , n. 2, p. 109-125, jul./dez. 2015.
Sandra Dutra Piovesan

\author{
Rosana Wagner
}

Roseclea Duarte Medina

Liliana Maria Passerino

\section{Introdução}

0 desenvolvimento tecnológico, além de transformar profundamente a sociedade em que vivemos, ampliou de forma vertiginosa a possibilidade de estabelecimento de processos de comunicação que permitem níveis de interação cada vez mais complexos 
e ao mesmo tempo naturais. À medida que novos recursos surgem, em que as tecnologias superam as limitações de representação de informações, passam também a nos oferecer não somente o texto como único suporte, mas uma infinidade de outros formatos, sendo possível apontar para uma potencialização dos processos de interação (MELLO; TEIXEIRA, 2012).

Reconhecer a importância dos processos interativos para o desenvolvimento humano e, em especial para o processo de aprendizagem de pessoas com deficiência intelectual, parece urgente, pois estas tecnologias têm ganhado espaço no meio educacional.

Desta forma, ao assumir que o processo de aprendizagem depende fundamentalmente de processos interativos, é preciso que se estabeleçam reflexões acerca dos fundamentos pedagógicos e inerentes à utilização de novos recursos que produzem novas formas de interação para o processo de aprendizagem e desenvolvimento de habilidades.

O Solassist Virtual é um projeto de cunho tecnológico e pesquisa qualitativa que desenvolveu uma tecnologia assistiva baseada em conceitos de Ambientes Imersivos para apoiar a inclusão de pessoas com deficiência no mercado de trabalho. Considerando a importância do trabalho para o desenvolvimento, a autoestima e a autonomia das pessoas com deficiência, entende-se que ainda há um grande caminho a percorrer no que se refere à inclusão destas pessoas nos ambientes produtivos a partir de processos educativos não formais.

Em 1990, no âmbito da administração pública, a Lei no 8.112 de 11 de dezembro, em seu artigo segundo, assegura às pessoas com deficiência não só o direito de se inscreverem em concursos públicos, cujas atribuições sejam compatíveis com sua deficiência, mas também garante a reserva de até vinte por cento das vagas oferecidas no concurso para estas pessoas.

A política com maior destaque foi a Lei 8.213 de 1991, a chamada Lei de Cotas. A partir de então, a atuação do governo tem procurado resguardar o direito ao trabalho das pessoas com deficiência através da fiscalização do cumprimento da referida Lei (BRASIL, 2004).

As formações de recursos humanos, principalmente as de caráter inicial, têm dado conta de forma incipiente de uma formação na área de Tecnologia Assistiva (TA). A tecnologia assistiva, enquanto recursos e serviços que contribuem para a vida independente das pessoas, tem tido um papel de destaque crescente em pesquisas voltadas para o desenvolvimento, escolarização e vida autônoma de pessoas com deficiência. Principalmente no que se refere ao o campo educacional, há um esforço para o desenvolvimento e uso das tecnologias visando à escolarização desses sujeitos, sua autonomia e inclusão social.

Contudo, estes dois temas, do trabalho e da tecnologia assistiva, no que se refere à inclusão de pessoas com deficiência intelectual, concorrem paralelamente, e aparentemente pouco têm se encontrado para produzir resultados conjuntos. O uso da tecnologia assistiva voltada para a inclusão de pessoas com deficiência no ambiente de trabalho é um recurso ainda pouco explorado a despeito de suas potencialidades (PEREIRA; PASSERINO, 2012).

Em particular nas empresas, tal preocupação parece não ser prioritária. Fica evidente que a lógica da contratação é a de que a pessoa e sua deficiência se adaptem ao posto de trabalho e não o contrário, existindo certo estereótipo de local de trabalho para cada deficiência, que revela estigma e posição (GOFFMAN, 1988). 


\section{Deficiência e Trabalho}

Os processos de exclusão vivenciados pelas pessoas com deficiência têm dificultado os acessos desses indivíduos a determinados setores, entre eles a educação e o mercado de trabalho. Em decorrência, a baixa escolaridade e o despreparo para desempenhar uma atividade laboral surgem. Diante disso, as oportunidades e o acesso ao mercado de trabalho ficam dificultadas ou até impossibilitadas. Quando se trata de deficiência intelectual, o cenário pode ser ainda mais excludente.

A International Association for the Scientific of Intellectual Disabilities (AAIDD) de 2002, cita que a deficiência intelectual é percebida nas pessoas antes dos dezoito anos de idade e caracteriza-se por limitações significativas no funcionamento intelectual e nas habilidades adaptativas. As limitações são compreendidas a partir de uma perspectiva multidimensional, proposta em cinco dimensões: habilidades intelectuais; comportamento adaptativo; participação, interação e papéis sociais; saúde física e mental e contextos relacionados ao ambiente e condições socioculturais (CARVALHO; MACIEL, 2003).

Desta forma, a deficiência intelectual deixa de ser identificada como um traço absoluto manifestado pela pessoa e classificada com base em níveis de coeficiente de inteligência (leve, moderado, severo e profundo), passando a ser compreendida como expressão da interação entre o indivíduo e o meio ambiente em que vive e avaliada a partir de níveis de apoio ou suporte necessários ao desempenho e exigências ambientais (CARVALHO; MACIEL, 2003).

Inclusão social, integração e a busca por uma sociedade mais acolhedora têm norteado várias pesquisas para apoiar uma melhoria na vida das pessoas com deficiência. É possível notar avanços com a preocupação destes temas em relação a novas formas de pensar e agir em relação à diversidade humana, com poder na formação de novos conceitos (SAETA, 1999).

O desenvolvimento da pessoa com deficiência é semelhante ao da pessoa normal. A diferença seria que as pessoas com deficiência não sabem utilizar recursos culturais, configurando-se numa limitação ou incompletude do desenvolvimento cultural, num comprometimento de suas funções psicológicas superiores (MAGALHÃES; FERNANDES, 2014).

A teoria sócio histórica de Vygotsky, elaborada nas décadas de 20 e 30, continua cumprindo um papel de destaque na compreensão da deficiência intelectual, influenciando práticas pedagógicas para inclusão destas pessoas no mercado de trabalho.

Vygotsky ressalta que a incompreensão das pessoas com deficiência reside na desconsideração das funções psicológicas superiores como novas possibilidades para o desenvolvimento. As características orgânicas continuarão a existir, mas podem ser substituídas ou redimensionadas através dessas funções, fomentadas a partir do convívio social e de inserção na cultura (MAGALHÃES; FERNANDES, 2014).

Segundo Carlo:

A pessoa com deficiência, comumente, é vista como aquela que se diferencia do tipo humano 'normal', entretanto, o desenvolvimento comprometido pela deficiência apresenta uma expressão qualitativamente peculiar que se diferencia conforme o conjunto de condições que se realiza [...] Porém, as leis do desenvolvimento são iguais para todas as pessoas (deficientes ou não) e a diferenciação do padrão biológico típico do homem implica uma alteração da forma de enraizamento 
do sujeito na cultura. A cultura provoca uma reelaboração do curso do desenvolvimento humano, sob novas condições e sobre novos fundamentos (DE CARLO, 1999, p. 77).

Explica-se assim, o fracasso das pessoas com deficiência quando se exige um desempenho que não condiz com o seu ritmo de desenvolvimento e aprendizado. Deve-se compreender como ocorre a aprendizagem das pessoas com deficiência intelectual, viabilizando um ensino que pondere e atenda as especificidades destes indivíduos.

Considera-se então, a noção de Zona de Desenvolvimento Proximal (ZDP) de Vygotsky, como categoria central no redimensionamento da educação das pessoas com deficiência intelectual. A ZDP, em termos mais gerais, trata-se de determinar a relação entre as pré-condições estabelecidas pelo nível de desenvolvimento prévio dos sujeitos e as possibilidades de aprendizagem consequentes. Operar sobre a ZDP possibilita trabalhar sobre as funções em desenvolvimento, ainda não plenamente consolidadas, mas sem necessidade de esperar sua configuração final para começar uma aprendizagem (BAQUERO, 1996).

Vygotsky enfatiza o processo de construção das aquisições com a mediação docente, em que se minimizaria, num primeiro momento, a noção de desenvolvimento real, as aquisições autônomas. O desenvolvimento intelectual só pode ser determinado se forem revelados os seus dois níveis: o nível de desenvolvimento real e a Zona de Desenvolvimento Proximal. De fato, o comprometimento do desenvolvimento espontâneo, próprio da deficiência intelectual, remete à viabilização de uma ação interventiva (VYGOTSKY, 1991).

Segundo Fonseca:
A aprendizagem depende, portanto, do desenvolvimento prévio e anterior, ao mesmo tempo que depende do desenvolvimento proximal do sujeito. Não estão só em causa as atividades que ele pode aprender com a ajuda e a intervenção intencional dos outros, ou seja, ele aprende por humanização, por meio de midiatização. As pessoas que rodeiam o sujeito, ou melhor, a criança (o mediatizado), não são objetos passivos ou simples instrumentos do seu desenvolvimento, mas sim companheiros ativos que guiam, planificam, regulam, selecionam, filtram, começam e terminam as condutas da criança. São agentes do seu desenvolvimento (FONSECA, 1998, p. 68).

Assim pode-se considerar na atividade de preparação desses indivíduos para o trabalho, um processo de capacitação através da mediação proposta por Vygotsky, tornando esses indevidos mais qualificados a desempenhar funções, abrindo portas ao mercado de trabalho.

A Lei de Cotas prevê que a quantidade de vagas que deve ser reservada para deficientes, mas devido a vários motivos esta lei nem sempre é seguida. Pesquisas mostram que estabelecimentos com menos de 100 funcionários, que por lei não têm obrigação de contratar pessoas com deficiência, apresentam uma taxa de empregabilidade média de $1,05 \%$. As empresas empregadoras de 100 a 200 funcionários são obrigadas a reservar $2 \%$ de seus postos para pessoas com deficiência, apresentam uma taxa de empregabilidade média de 2,7\%. Nas empresas com 201 a 500 empregados, verifica-se uma taxa de empregabilidade de $2,9 \%$ contra a cota exigida por lei de $3 \%$. Quando são examinadas empresas que possuem de 501 a 1000 empregados, observamos uma taxa de empregabilidade de $2,8 \%$ contra $4 \%$ da cota exigida. Descumprimento similar à lei é observado nas empresas com mais de 1000 funcionários, pois a legislação determi- 
na que essas empresas ofereçam pelo menos $5 \%$ de seus postos de trabalho às pessoas com deficiência contra 3,6\% da taxa de empregabilidade média observada na prática (SANTOS, 2008).

O Brasil conta com 45 milhões de pessoas com deficiência, segundo o Instituto Brasileiro de Geografia e Estatística (IBGE). Essas pessoas, porém, não circulam nas ruas, nas escolas comuns, nos locais de lazer e cultura e muito menos têm acesso ao trabalho. Os problemas que daí decorrem refletem-se na baixa escolaridade desse grupo, grande dificuldade de inserção social, de constituição de vínculos familiares para além dos lares paternos e maternos (IBGE, 2012).

A presença de alunos com deficiência nos espaços de formação profissional ainda é inexpressiva, o que dificulta sobremaneira o acesso desse segmento social ao mundo laboral. Sem essa capacitação para o trabalho, que propicia a aquisição de comportamentos, conhecimentos e habilidades necessários ao desempenho profissional, às pessoas com deficiência, são reservadas vagas que exigem escassa ou nenhuma qualificação e que, por decorrência, remuneram com os menores salários e não gozam do reconhecimento corporativo e social. Tal situação acarreta profissionalmente desvantagens nos processos de ascensão profissional e até mesmo para a manutenção do emprego (COSTA, 2013).

Os estabelecimentos empresariais são obrigados a contratar aprendizes num percentual de $5 \%$ a $15 \%$ das funções que demandem formação profissional. Através desse contrato, além da capacitação, aos aprendizes, é garantida anotação na carteira de trabalho, o piso regional de salário mínimo proporcional às horas de curso, Fundo de Garantia do Tempo de Serviço (FGTS), férias e outros direitos trabalhistas e previdenciários regulamentos no Decreto $n^{\circ}$ 5.598/2005. Destaca-se que o aprendiz nada paga por essa formação (COSTA, 2013).

Esses programas de qualificação preveem tanto atividades teóricas como práticas e são organizados e desenvolvidos sob a orientação de entidades qualificadas em formação técnico-profissional. Enquanto a formação prática é realizada na empresa, a teórica é fornecida pelo Sistema S (SENAI, SENAC, SENAR, SENAT E SESCOOP). Quando essas instituições não fornecem vagas suficientes, a demanda pode ser suprida pelas escolas técnicas de educação e entidades sem fins lucrativos. Sendo assim o contrato de aprendizagem contempla obrigatoriamente uma relação triangular que envolve: o aprendiz, a empresa e a entidade formadora (COSTA, 2013).

As oportunidades de acesso ao trabalho das pessoas com deficiência ocorrem de forma lenta e começam a ser incentivadas por meio de fiscalização mais efetiva do Ministério Público do Trabalho (Decreto no 3299/99), mediante punições às empresas que não vêm cumprindo com a lei (FERRONATTO; WAGNER; FALKENBA$\mathrm{CH}, 2008$ ). A fiscalização tornou o tema mais público e possibilitou maior conscientização da população quanto à necessidade de promoção da qualificação destas pessoas (MENDONÇA, 2007).

\section{Tecnologias Assistivas e Ambien- tes Imersivos}

O conceito de Tecnologia Assistiva proposto pelo Comitê de Ajudas Técnicas (CAT) é uma instância que estuda essa área do conhecimento no âmbito da Secretaria Especial dos Direitos Humanos da Presidência da República 
(SEDH/PR). O conceito aprovado e adotado por este Comitê estabelece que:

Tecnologia Assistiva é uma área do conhecimento, de característica interdisciplinar, que engloba produtos, recursos, metodologias, estratégias, práticas e serviços que objetivam promover a funcionalidade, relacionada à atividade e participação de pessoas com deficiência, incapacidades ou mobilidade reduzida, visando sua autonomia, independência, qualidade de vida e inclusão social (CAT, 2007).

Toda ferramenta, recurso, estratégia ou processo desenvolvido e utilizado com a finalidade de proporcionar maior independência e autonomia a pessoa com deficiência pode ser considerado como TA (HAZARS; GALVÃO FILHO; REZENDE, 2007).

Apesar da crescente demanda da área, em nosso país, as pesquisas e projetos de TA ainda são escassos. O tema, na maior parte das vezes, fica restrito aos especialistas envolvidos com pessoas com deficiência, como se esse assunto não coubesse na pauta de discussões e ações de outras áreas do conhecimento (RODRIGUES; ALVES, 2013).

Ambiente Imersivo é o termo usado para definir direta ou indiretamente um ambiente do mundo real, cujos elementos são combinados com elementos virtuais para criar uma realidade mista em tempo real (KIRNER, 2012).

Um Sistema Imersivo torna possível uma aprendizagem autônoma, através da aprendizagem do interagir virtual, com o desenvolvimento de competências e modificações dos esquemas cognitivos, onde os limites poderão ser expandidos. Cabe, portanto analisar o papel que a interação mediada desempenha nessa nova modalidade de ensino aprendizagem, quando utilizados com pessoas com deficiência intelectual.

\section{Aprendizagem com Tecnologia}

A teoria de Vygotsky propõe que o desenvolvimento cognitivo só se dá por meio da interação social, onde no mínimo duas pessoas estão envolvidas ativamente na troca de experiências, gerando assim novos conhecimentos.

Vygotsky chamou de funções mentais superiores aos processos tipicamente humanos como: memória, atenção e lembrança voluntária, memorização ativa, imaginação, capacidade de planejar, estabelecer relações, ação intencional, desenvolvimento da vontade, elaboração conceitual, uso da linguagem, representação simbólica das ações propositadas, raciocínio dedutivo e pensamento abstrato (JOENSK, 2002).

A limitação do indivíduo, quando portador de deficiência, tende a tornar-se uma barreira a este aprendizado. Desenvolver recursos seria uma maneira concreta de neutralizar as barreiras e inserir esse indivíduo nos ambientes ricos para a aprendizagem, proporcionados pela cultura (DAMASCENO; GALVÃO FILHO, 2002).

É sabido que as novas tecnologias vêm se tornando, de forma crescente, importantes instrumentos de nossa cultura e, sua utilização, um meio concreto de inclusão e interação no mundo. Esta constatação é ainda mais evidente e verdadeira quando nos referimos a pessoas com deficiência. Nestes casos, as tecnologias podem ser utilizadas como Tecnologia Assistiva (DAMASCENO; GALVÃO FILHO, 2002).

Mediação é o processo de intervenção de um elemento intermediário numa relação, que deixa de ser direta e passa a ser mediada por esse elemento. Quando uma criança agarra o caule de uma rosa e retira a mão ao sentir a dor causada pelo espinho, está estabelecida uma relação direta entre o espinho e a retira- 
da da mão. Se, em outra ocasião, a criança, ao ver a rosa, examinar o caule verificando a existência de espinhos, a relação estará mediada pela lembrança da experiência anterior. Entretanto, se noutra ocasião, a criança observar o caule da rosa quando a mãe the disser que ela pode ferir sua mão num espinho, a relação estará mediada pela intervenção da mãe (JOENSK, 2002).

A pessoa com deficiência precisa de metodologias diferenciada, para que ocorra o processo de ensino-aprendizagem, a fim de obter um pensamento abstrato (VYGOTSKY, 1997).

Para Vygotsky (1991) o ensino da pessoa com deficiência intelectual deve visar a superação das dificuldades inatas, isto significa que, é preciso a todo o momento impulsioná-las a desenvolver o pensamento abstrato e aprimorar nestes sujeitos aquilo que está faltando no seu próprio desenvolvimento. Um Sistema Imersivo torna possível uma aprendizagem autônoma, através da aprendizagem do interagir virtual, com o desenvolvimento de competências e modificações dos esquemas cognitivos, onde os limites poderão ser expandidos. Cabe, portanto analisar o papel que a interação mediada desempenha nessa nova modalidade de ensino aprendizagem, quando utilizados com pessoas com deficiência intelectual.

\section{Metodologia}

Para Vygotsky (1991) o ensino da pessoa com deficiência intelectual deve visar a superação das dificuldades inatas, isto significa que, é preciso a todo o momento impulsioná-las a desenvolver o pensamento abstrato e aprimorar nestes sujeitos aquilo que está faltando no seu próprio desenvolvimento. Um Sistema Imersivo torna possível uma aprendizagem autôno- ma, através da aprendizagem do interagir virtual, com o desenvolvimento de competências e modificações dos esquemas cognitivos, onde os limites poderão ser expandidos. Cabe, portanto analisar o papel que a interação mediada desempenha nessa nova modalidade de ensino aprendizagem, quando utilizados com pessoas com deficiência intelectual.

A pesquisa Solassist Virtual foi realizada dentro do Grupo Tecnologia em Educação para Inclusão e Aprendizagem em Sociedade (TEIAS) da Universidade Federal do Rio Grande do Sul (UFRGS). Trata-se de uma pesquisa qualitativa e de desenvolvimento tecnológico a partir do método estudo de caso.

A ênfase geral desta pesquisa será de cunho qualitativo sendo o estudo de caso seu método principal (YIN, 1993, STAKE, 1999) com técnicas de coleta que envolve observação, entrevista e análise de registros para garantir a triangulação dos dados.

Para alcançar os objetivos e metas deste projeto, foram realizadas algumas etapas e procedimentos descritos a seguir.

Revisão bibliográfica e Análise das produções acadêmicas já existentes relativa à temática de desenvolvimento de sistema imersivos utilizando técnicas de realidade virtual, pessoas com deficiência e tecnologias assistiva, que foram realizadas em espaços como o portal de periódicos da Coordenação de Aperfeiçoamento de Pessoal de Nível Superior (CAPES), bibliotecas digitais das universidades, sites de associações científicas, dentre outros veículos.

O Laboratório de Modelagem foi realizado para selecionar o framework de modelagem do sistema. Foi selecionado o motor de jogo Unreal Development Kit ou UDK4. A UDK é uma derivação da Unreal Game Engine, criada pela empresa Epic, e trata-se de uma versão gratuita do motor. 
Foi realizada uma busca por uma Empresa interessada na Pesquisa. A Empresa apresentou interesse em participar do projeto, disponibilizando a sua estrutura para ser modelada e onde serão realizadas as intervenções com os sujeitos que participarão da pesquisa. A empresa possui um termo de concordância em participação com o grupo de pesquisa, sendo que o mesmo se encontra assinado pelo gestor responsável e também pelos funcionários que participaram diretamente na pesquisa.

Observação direta do ambiente de trabalho na empresa e análise preliminar dos casos selecionados para acompanhamento e uso inicial do sistema. A escolha dos sujeitos com deficiência foi indicada pela instituição participante.

A observação aconteceu para conhecer a instituição, delimitar o escopo do ambiente, mapear as funcionalidades e a partir de entrevistas com gestores e responsáveis pelos Recursos Humanos (RH) e também de observação direta não participante, obter o máximo de conhecimento sobre o espaço físico e sobre as funcionalidades que o sistema deve possuir. Essa observação também servirá para identificar as habilidades que os usuários possuem para assim fornecer recursos adequados. $O$ sistema foi desenvolvido procurando reproduzir da forma mais fiel a empresa.

Nesta definição a semelhança foi de ambiente e dos objetos, reproduzindo assim o ambiente que o sujeito encontrará futuramente no ambiente de trabalho. A Figura 1 apresenta o sistema desenvolvido e ao lado uma foto da empresa, demonstrando assim a fidelidade na modelagem.
Figura 1 - Empresa Modelada

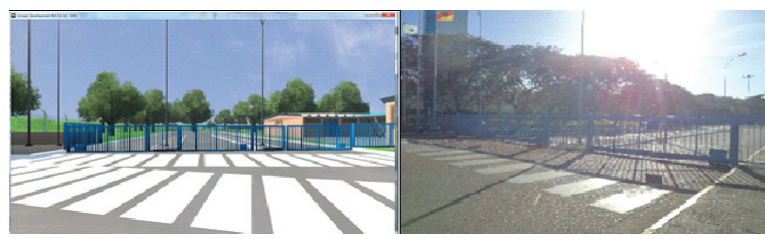

Fonte: Elaborado pelos próprios autores.

Nesta etapa foram realizadas avaliações do ambiente pelos próprios funcionários da empresa selecionada, buscando chegar ao mais próximo do real ambiente que será encontrado pelos sujeitos que participarão das pesquisas. A produção dos materiais que serão utilizados dentro do mundo para as interações com os sujeitos precisa ser cuidadosamente modelada para que a simulação seja adequada.

Utilizaram-se vídeos com as principais funções que devem ser desempenhadas pelos sujeitos quando forem inseridos no ambiente real de trabalho. Esses vídeos tratam das situações prováveis de acontecerem dentro da empresa, de situações pouco prováveis e também das improváveis, tentando englobar ao máximo as situações que poderão ocorrer neste ambiente de trabalho.

A identificação dos usuários do sistema aconteceu no mês de Abril de 2014. A Empresa, juntamente com o Escola Municipal de Ensino Especial Cebolinha onde a Associação de Pais e Amigos dos Excepcionais (APAE) presta atendimento especializado, localizada em Gravataí e com o Serviço Nacional de Aprendizagem Industrial Departamento Nacional (SENAI) iniciou uma turma destinada a trabalhar especificamente na empresa. O curso teve durante de um ano, sendo que seis meses do curso, ou seja, a parte teórica foi realizada na Escola Municipal de Ensino Especial Cebolinha e os outros seis meses, que englobam ativida- 
des práticas, foram realizados dentro da própria Empresa.

Foram realizadas visitas durante as aulas dos alunos na Escola Municipal de Ensino Especial Cebolinha, para que se pudesse ter um maior conhecimento sobre os sujeitos que fariam uso do sistema e assim mais uma vez tentar deixá-lo o mais adequado possível a esses usuários. As visitas também serviram para identificar o tipo de deficiência e o grau de comprometimento de cada estudante.

Com o estudo prévio do público alvo do sistema, foi possível identificar as habilidades de comunicação e de interação assim como o desenvolvimento motor e cognitivo, de forma individual.

O professor responsável por ministrar a parte teórica do curso aos alunos da empresa realizou uma avaliação do ambiente. Nesta avaliação o professor responsável pelo Curso Auxiliar de Linha de Produção, da Área Profissional Automotiva na Modalidade Aprendizagem Industrial Básica, com Carga Horária de 800 horas, procurou identificar as funcionalidades do sistema para que fosse possível a inclusão do sistema nas aulas teóricas de acordo com o Projeto Pedagógico do Curso (PPC) do curso.

Foram selecionados os componentes curriculares do curso onde o sistema poderia ser usado e a forma de intervenção mais adequada para os usuários.

As intervenções utilizando o sistema e roteiro de entrevistas: durante os meses de junho até setembro de 2014 foram realizadas intervenções no ambiente, onde os usuários fizeram uso do sistema de forma livre e também foram orientados a explorarem alguns lugares do ambiente. As intervenções foram realizadas com entrevistas informais onde se buscou identificar as habilidades individuais, como a facilidade de utilização do ambiente, o uso do mouse e o interesse sobre o sistema. O sistema também foi utilizado com um recurso de projeção, onde os alunos em conjunto puderam expor suas considerações sobre o sistema de forma livre. Foram convidados a falarem o que gostaram no sistema e os pontos que consideraram fracos, buscou-se dessa forma então, identificar possíveis melhorias para um nova versão.

Acompanhamento após o uso do sistema: com a conclusão das intervenções foram realizadas visitas durante as aulas teóricas dos alunos na busca por indícios de que o sistema possa ter ajudado na assimilação dos componentes para os quais foi selecionado. Durante essas visitas procurou-se somente observar o comportamento e identificar a assimilação de algum conteúdo trabalhado no sistema.

Análise dos Dados: O referencial teórico estudado, juntamente com utilização do sistema, forneceu uma variedade de dados que embasaram a formação de categorias de análise. O processo de análise está fundamentado na teoria sócio-histórica, utilizando os conceitos de mediação apresentados por Vygotsky (2001). Assim, relembrando que mediação ou ação mediadora é toda a ação desenvolvida na interação social pelos sujeitos a partir do uso de instrumentos de mediação que pode estar orientada ao próprio sujeito, aos outros sujeitos ou ao meio físico. Através do processo de mediação buscou-se mudanças qualitativas no sujeito, dependendo assim da internalização das atividades que ele deve desempenhar dentro do ambiente laboral, através do uso do sistema desenvolvido.

As categorias elencadas durante a realização do estudo com os participantes da pesquisa foram: apropriação, comunicação e motivação. 
A categoria apropriação está relacionada ao que o usuário demonstra ter assimilado durante a realização da pesquisa. Está ligado à demonstração, que através do uso do sistema, adquiriu algum conhecimento que não possuía anteriormente. Esta categoria também engloba os conceitos de utilização do sistema de realidade virtual, como entrar no sistema, como acessar os objetos de aprendizagem, como se movimentar no sistema, etc., assim como a apropriação dos conteúdos específicos ao qual o sistema foi desenvolvido, localização e movimentação adequada dentro da empresa, comportamento no refeitório e utilização correta dos equipamentos de segurança.

A categoria de comunicação se relaciona com a habilidade que o usuário demonstra durante as mediações realizadas com o sistema de dialogar de forma coerente sobre os componentes que estão sendo apresentados. É através da comunicação que o usuário troca informações, faz questionamentos e expressa suas dúvidas e assim demonstra as habilidades que estão sendo adquiridas. A inabilidade de comunicação pode levar a incompreensão do uso do sistema, acarretando assim prejuízo na assimilação dos conteúdos apresentados.

A categoria de motivação buscou investigar o interesse que os estudantes têm pelo uso do sistema. É através da motivação que o indivíduo direciona sua atenção e é considerada um dos fatores mais relevantes para a promoção da aprendizagem.

Aspectos éticos e legais: a presente pesquisa foi encaminhada ao comitê de ética para apreciação, com parecer de aprovação número 508395, na data de 09 de janeiro de 2014.

\section{Análise e Interpretação dos Da- dos}

O estudo foi realizado com um grupo de alunos que participaram do programa que prevê a formação técnica-profissional para posterior contratação laboral. O grupo de alunos realizou a parte teórica do curso numa escola do SENAI, já descrita anteriormente, local onde ocorreram as intervenções com o uso do sistema imersivo.

O grupo era composto de 11 alunos, sendo que todos foram diagnosticados com deficiência intelectual leve, sendo que três desses alunos também tinham Síndrome de Down. A faixa etária é bastante variada, iniciando em 19 anos até 32 anos. Dos 11 alunos que participaram da pesquisa, apenas dois deles não haviam realizado nenhuma atividade laboral remunerada anteriormente a realização do curso. A Figura 2 apresenta um dos alunos participantes utilizando o sistema.

Figura 2 - Aluna Utilizando o sistema

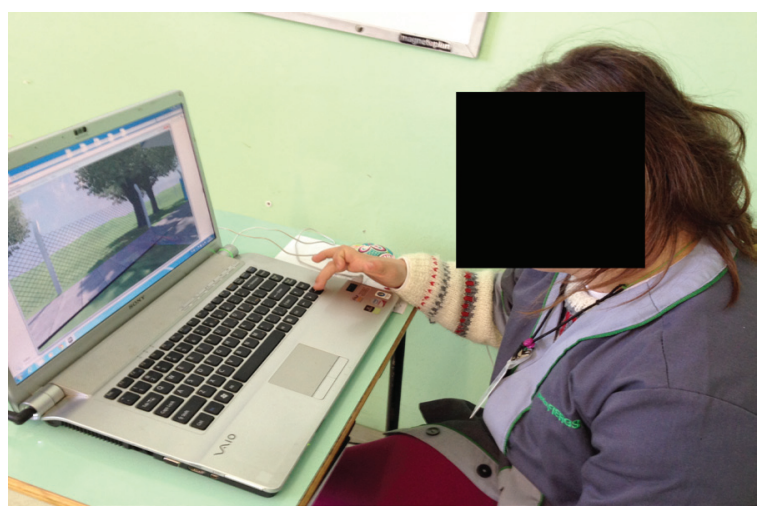

Fonte: Elaborado pelos próprios autores.

A Aluna 1 é do sexo feminino, com 28 anos de idade e já havia tido outros trabalhos remunerados anteriores a pesquisa, tendo diagnós- 
tico de deficiência intelectual leve. A Aluna 2 é do sexo feminino, com 22 anos de idade, já trabalhou de forma remunerada antes da realização da pesquisa, apresentando deficiência intelectual leve e também Síndrome de Down. A Aluna 3 é do sexo feminino, com 18 anos de idade, ainda não trabalhou de forma remunerada antes da realização da pesquisa, sendo diagnosticada com deficiência intelectual leve. O Aluno 4 é do sexo masculino, com 32 anos de idade, já trabalhou de forma remunerada antes da realização da pesquisa, apresentando deficiência intelectual leve e também Síndrome de Down. Esses alunos citados utilizaram com facilidade o sistema, se mostrando bastante motivados, sendo que já no primeiro dia de uso do sistema reconheceram a empresa. Estes alunos estão na categoria Motivação Alta. Durante as intervenções, esses alunos prestaram bastante atenção, sendo que quanto à categoria Apropriação, estão enquadrados como alta, pois conseguiram localizar lugares com facilidade dentro do sistema e também respondiam corretamente quando questionados sobre o que eram alguns equipamentos. Os Alunos se comunicam com bastante clareza, entendem as questões propostas e respondem de forma coerente, estando assim na categoria de Comunicação Alta.

A Aluna 5 é do sexo feminino, com 26 anos de idade, já trabalhou de forma remunerada antes da realização da pesquisa. Apresenta deficiência intelectual leve. Apesar da Aluna 3 estar realizando o curso juntamente com os alunos da Dana, não irá trabalhar na empresa, pois já foi contratada por outra empresa. Utilizou o ambiente com facilidade, porém como não ficará no grupo, os dados desta aluna não foram analisados.

O Aluno 6 é do sexo masculino, com 31 anos de idade, já trabalhou de forma remunerada antes da realização da pesquisa. Apresenta deficiência intelectual leve. O Aluno 6 reclamou que falta áudio nos vídeos do sistema, mas disse que é muito bom o sistema. Aluno bastante interessado, mostrou inclusive que tem conhecimentos de informática. Estando enquadrado na categoria Motivação Alta. O Aluno solicitou que fossem acrescentadas as fábricas e disse que sabe que nas fábricas e bastante perigoso. Possui bastante facilidade de comunicação, estando enquadrado na Categoria Comunicação Alta, porém bastante disperso. Durante todas as intervenções foi necessário solicitar a atenção para os vídeos, estando assim enquadrado como Apropriação Média, pois quando solicitado sobre os conteúdos apresentou dificuldade nas respostas.

O Aluno 7 é do sexo masculino, com 19 anos de idade, já trabalhou de forma remunerada antes da realização da pesquisa. Apresenta deficiência intelectual leve. Utilizou com facilidade o ambiente, porém foi necessário solicitar atenção aos vídeos, mesmo assim conseguiu identificar os locais no sistema, caminhando até os locais solicitados, estando assim enquadrado na Categoria Apropriação Alta. O Aluno 7 comentou que gosta das aulas no computador, porém nunca tinha utilizado, preferindo assim as aulas no sistema do que do modo tradicional. Por essas colocações ficou enquadrado na Categoria Motivação Alta. Tem bastante facilidade de responder aos questionamentos durante as intervenções, estando na Categoria de Comunicação Alta.

O Aluno 8 é do sexo masculino, com 37 anos de idade, já trabalhou de forma remunerada antes da realização da pesquisa. Apresenta deficiência intelectual leve. Apesar do Aluno 8 estar realizando o curso juntamente com os alunos da Dana, não irá trabalhar na empresa, pois já foi contratado por outra empresa. 
Utilizou o ambiente com facilidade, comentou que gosta de usar o computador e já possuía alguns conhecimentos de informática, porém como não ficará no grupo, os dados deste aluno não foram analisados.

O Aluno 9 é do sexo masculino, com 18 anos de idade, ainda não trabalhou de forma remunerada antes da realização da pesquisa. Apresenta deficiência intelectual leve e também Síndrome de Down. Utilizou de maneira tranquila, por indicação do professor foi solicitado que mostrasse várias vezes como é a utilização das catracas através do sistema, pois ele mostrou bastante dificuldade na utilização das catracas e do crachá. Apesar da orientação durante as intervenções, o aluno continuou apresentando dificuldade em algumas das solicitações do professor, estando assim, enquadrado na Categoria Apropriação Média. O Aluno é bastante disperso, inclusive interrompe o uso do sistema quando verifica que tem algum colega jogando bola, se mostrando bastante desatento. Este aluno está enquadrado na Categoria Motivação Baixa. Quanto a comunicação, o Aluno também apresenta dificuldade de entender o que foi solicitado, respondendo de maneira não coerente na maioria das vezes que foi questionado, estando assim enquadrado na Categoria Comunicação Baixa.

O Aluno 10 é do sexo masculino, com 23 anos de idade, ainda não trabalhou de forma remunerada antes da realização da pesquisa. Apresenta deficiência intelectual severa. O Aluno 10 apresentou muita dificuldade na utilização do ambiente, porém depois de algum tempo conseguiu utilizar, com um pouco de dificuldade em se movimentar no sistema, estando assim enquadrado na Categoria Apropriação Baixa. 0 Aluno 10 não respondeu nenhuma pergunta e não fez nenhum questionamento, se manteve durante todas as intervenções como se estive sozinho, mas se mostrou interessado na utilização do sistema, estando assim enquadrado nas Categorias Apropriação Baixa e Motivação Alta. Durante toda a utilização sorria enquanto utilizava o sistema. Tentava utilizar outras teclas do computador mesmo sendo orientado para não utilizar, mostrando assim que não compreendia o que estava sendo solicitado, estando enquadrado na Categoria Comunicação Baixa.

O Aluno 11 é do sexo masculino, com 27 anos de idade, já trabalhou de forma remunerada antes da realização da pesquisa. Apresenta deficiência intelectual leve. Este aluno foi uma exceção, pois apesar dos vários convites, não quis usar o ambiente, porém ficou diversas vezes atrás dos colegas que estavam utilizando o sistema. Este aluno fica então, enquadrado nas categorias Motivação Baixa e Apropriação Baixa. Apesar de não ter utilizado o sistema, o aluno conversava de forma adequada nas aulas teóricas do professor quando observado, estando assim enquadrado na Categoria Comunicação Alta.

A partir da categorização dos alunos tornou-se possível a criação de grupos, onde seus integrantes compartilham de características semelhantes quanto a utilização do sistema:

- Grupo 1: Este grupo apresentou apropriação alta, motivação alta e comunicação alta. Ficaram neste grupo 4 alunos, sendo o maior agrupamento de alunos deste estudo. Este grupo apresentou os alunos que se mostraram bastante motivados a utilizar o sistema, também com uma comunicação muito boa, pois quando questionados, respondiam de acordo, com respostas coerentes ao que estava sendo proposto. Também foi possível identificar com facilidade os conceitos apropriados a partir da utilização do sistema. 
- Grupo 2: Este grupo apresentou apropriação média, motivação alta e comunicação alta. Ficaram neste grupo dois alunos, sendo o desempenho deste grupo ficou um pouco abaixo do grupo 1 na categoria apropriação. Assim como o grupo 1 , este grupo teve muito interesse na utilização do sistema e também respondeu de forma correta aos questionamentos propostos, porém ficou menos evidente a assimilação dos conceitos estudados, apesar da facilidade de utilização do sistema.

- Grupo 3: Este grupo apresentou apropriação média, motivação baixa e comunicação baixa. Ficou neste grupo apenas um dos alunos estudados. Este aluno apresentou uma motivação baixa em utilizar o sistema, respondeu pouco as perguntas realizadas durante as intervenções, porém pode-se constatar que houve facilidade da utilização do sistema e que alguns dos conceitos estudados no sistema foram assimilados.

- Grupo 4: Este grupo de alunos apresentou apropriação baixa, motivação alta e comunicação baixa. Foi enquadrado neste grupo apenas um dos alunos do estudo. Apesar do aluno mostrar uma motivação bastante alta na utilização do sistema, ele não respondeu aos questionamentos e apresentou bastante dificuldade na utilização do sistema, mesmo com o auxílio do professor. Este aluno teve dificuldade em utilizar o mouse e as teclas do computador de forma coerentes, ficando andando pelo ambiente sem objetivo definido.

- Grupo 5: Este grupo de alunos apresentou apropriação baixa, motivação baixa e comunicação alta. Neste grupo ficou apenas um dos alunos do estudo. Este aluno não aceitou utilizar o sistema, apenas observou a utilização dos colegas. Apesar de não participar da utilização do sistema, possui ótima comunicação, justificou a não utilização por medo de estragar a computador e de não saber como fazer.

O Gráfico 1 apresenta a divisão dos alunos de acordo com os grupo criados. Pode-se verificar que a maioria dos alunos apresentou um desempenho satisfatório na utilização do sistema, pois ficaram enquadrados nos grupos 1 e 2. O grupo 1 foi o maior grupo de alunos com cerca de $45 \%$ dos alunos participantes da pesquisa. No grupo 2 ficaram 22\% dos alunos. Já os grupos 3, 4 e 5 ficaram $11 \%$ dos alunos estudados em cada grupo.

Gráfico 1 - Grupos de Análise

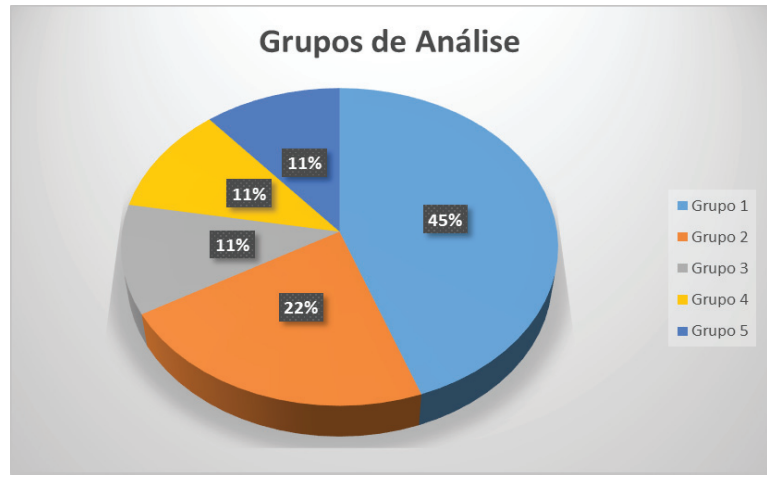

Fonte: Elaborado pelos próprios autores.

A partir dos dados coletados e apresentados no Gráfico 1, pode-se verificar que a grande maioria dos alunos 67\% (grupos 1 e 2 ) apresentaram uma motivação alta na utilização do sistema e uma comunicação adequada quando questionados durante e depois das intervenções no sistema. A apropriação dos conceitos 
estudados através da utilização do sistema também se mostrou bastante satisfatória, pois estes dois grupos assimilaram os conteúdos estudados, demonstrando grande facilidade na utilização dos recursos oferecidos pelo sistema.

\section{Considerações Finais}

O desenvolvimento do sistema se mostrou eficiente, possibilitando assim a criação de um ambiente imersivo fiel as características reais da empresa, podendo este ser observados pelos próprios alunos que desde as primeiras intervenções reconheceram a empresa e os lugares modelados. Este sistema se mostrou uma poderosa tecnologia assistiva, podendo ser usado como recurso didático e posteriormente como sistema de localização dentro da empresa, servindo assim para todos os funcionários.

Através da análise das mediações realizadas foi possível a criação de categorias e posteriormente de grupos, onde foi observado características comuns entre os alunos. Com estes grupos ficou visível a apropriação de conteúdos e conceitos estudados através do sistema criado. Durante as intervenções no sistema também foi verificado que houve apropriação de conhecimentos referentes a utilização do computador, como onde ligar, onde desligar, como mover o mouse, como utilizar o teclado, pois a maioria dos alunos nunca tinha tido nenhum contato com este equipamento.

A análise de como um sistema imersivo pode ser inserido no processo de educação visando inclusão de pessoas com deficiência intelectual no mercado de trabalho foi o objetivo mais importante desta pesquisa, sendo que o sistema desenvolvido se mostrou capaz de aumentar as possibilidades de auxílio para pessoas com deficiência, sendo este um recurso extremamente valioso, pois permite facilitar todo o processo educacional que visa a formação integral de cada aluno.

A ação mediada utilizando um instrumento de mediação, uma ferramenta com o auxílio de um professor cumpre um papel importante no processo de aprendizagem, possibilitando que alunos com deficiência intelectual se apropriem de saberes de forma mais rápida e com interesse maior dos estudantes.

A tecnologia deve ser encarada como um elemento cognitivo capaz de facilitar a estrutura de um trabalho, pois facilita as descobertas, garantindo, assim, condições propícias para a construção do conhecimento. Assim, o uso da tecnologia pode despertar o interesse e a motivação pela descoberta do conhecimento. A deficiência não deve ser encarada como uma impossibilidade, onde o uso das tecnologias pode desempenhar um papel significativo. 


\section{Referências}

BAQUERO, Ricardo. Vygostsky e a Aprendizagem Escolar. São Paulo: Artes Médicas, 1996.

BRASIL. Câmara dos Deputados. Legislação Brasileira Sobre Pessoas Portadoras de Deficiência. Brasília: Câmara dos deputados, Coordenação de Publicações, 2004.

DE CARLO, Marysia Mara Rodrigues do Prado. Se Essa Casa Fosse Nossa...: instituições e processos de imaginação na educação especial. São Paulo: Plexus Editora, 1999.

CARVALHO, Erenice Natália Soares; MACIEL, Diva Maria Moraes Albuquerque. Nova concepção de Deficiência Mental Segundo a American Association on Mental Retardation - AAMR: sistema 2002. Temas em Psicologia, Ribeirão Preto, SP, v. 11, n. 2, p. 147-156, 2003.

CAT. Ata da VII Reunião do Comitê de Ajudas Técnicas - CAT (CORDE/SEDH/PR) realizada nos dias 13 e 14 de dezembro de 2007. Brasília, 2007. Disponível em: <http://www.infoesp.net/CAT_Reuniao_VII.pdf> Acesso em: 12 jan. 2014.

COSTA, Ana Maria Machado. Inclusão Gradual no Trabalho: Aprendizagem Profissional. In: PASSERINO, Liliana M. et al. (Org.). Comunicar Para Incluir. Porto Alegre: CRBF, 2013. P. 61-79.

DAMASCENO, Luciana Lopes; GALVÃO FILHO, Teófilo Alves. As Novas Tecnologias Como Tecnologia Assistiva: utilizando os recursos de acessibilidade na Educação Especial. In: CONGRESSO IBERO-AMERICANO DE INFORMÁTICA NA EDUCAÇÃO ESPECIAL (CIIEE), 3., 2002, Fortaleza. Anais. Fortaleza: MEC, 2002. Disponível em: <http://www.galvaofilho.net/comunica.htm> Acesso em: 13 jan. 2014. dia mês abreviado ano.

FERRONATTO, Bianca Correia; WAGNER, Luciane Carniel; FALKENBACH, Atos Prinz. Inclusão Laboral da Pessoa Portadora De Deficiência. Revista Digital, Buenos Aires, año 12, n. 117, febr. 2008. Disponível em: <http://www.efdeportes.com> Acesso em: 12 fev. 2008.

FONSECA, Vitor. Aprender a Aprender: a educabilidade cognitiva. Porto Alegre: ARTMED, 1998.

JOENSK, Inhelora Kretzschmar. Uma Introdução ao Pensamento de Vygotsky. Revista Linhas, Florianópolis, v. 3, n. 1, 2002. Disponível em: <http://www.periodicos.udesc.br/index.php/linhas/article/ download/1276/1087> Acesso em: 3 dez. 2014.

GOFFMAN, Erving. Estigma: notas sobre a manipulação da identidade deteriorada. 4. ed. Rio de Janeiro: LTC, 1988. 
HAZARS, Damian; GALVÃo FILHO, Teófilo Alves; REZENDE, André Luiz Andrade. Inclusão Digital e Social de Pessoas com Deficiência: textos de referência para monitores de telecentros. Brasília: UNESCO, 2007.

IBGE. Censo Demográfico 2010: características gerais da população, religião e pessoas com deficiência. Rio de Janeiro, 2012. Disponível em: <http://biblioteca.ibge.gov.br/visualizacao/periodicos/94/ cd_2010_religiao_deficiencia.pdf> Acesso em: 6 dez. 14.

KIRNER, Claudio (Org.). Realidade Virtual e Aumentada. [site]. [S.I.: s.n.], 2012. Disponível em: <http://www.realidadevirtual.com.br> Acesso em: 11 mar. 2012.

MAGALHÃES, Suzana Marly Costa; FERnANDES, Maria Lourdes Carvalho Nunes. A Deficiência Mental na Perspectiva de Piaget e Vygotsky. In: INTRODUÇÃo à Educação. Brasília: FE/UNB, 2014. Disponível em: <http://www.fe.unb.br/introeducacaounb/?p=192> Acesso em: 4 jan. 2014.

MELLO, Elisângela Fátima Fernandes; TEIXEIRA, Adriano Canabarro. A Interação Social Descrita por Vigotski e a sua Possível Ligação com a Aprendizagem Colaborativa Através das Tecnologias de Rede. [S.I.: s.n.], 2012. Trabalho apresentado no IX Seminário de Pesquisa em Educação da Região Sul (ANPED SUL), 2012, Caxias do Sul, BR-RS. Disponível em: <http://www.ucs.br/etc/conferencias/ index.php/anpedsul/9anpedsul/paper/viewFile/6/871> Acesso em: 6 dez. 2014.

MENDONÇA, Rita Cássia Tenório. Breves Comentários Sobre os Dispositivos Legais que Subsidiam a Política de Inclusão das Pessoas com Deficiência no Mercado de trabalho. In: REDE Saci. [site] [São Paulo], 2007. Disponível em: <http//:saci.org.br/index.php?modulo=akemi\&parametro=19683> Acesso em: 22 jun 2014.

PEREIRA, Ana Cristina Cypriano; PASSERINO, Liliana Maria. Tecnologia Assistiva e Acessibilidade no Mercado de Trabalho: uma história de desencontros. Informática na Educação: teoria e prática, Porto Alegre, v. 15, n. 2, p. 171-181., jul./dez. 2012.

RODRIGUES, Patrícia Rocha; ALVES, Lynn Rosalina Ganna. Tecnologia Assistiva: revisão do tema. HoIos, Natal, RN, ano 29, v. 6, p. 170-180, 2013.

SAETA, Beatriz Regina Pereira. O Contexto Social e a Deficiência. Psicologia: Teoria e Pratica, São Paulo, v. 1, n. 1, p. 51-55, 1999. Disponível em: < http://editorarevistas.mackenzie.br/index.php/ptp/ article/download/1141/838> Acesso em: 4 jan. 2014.

SANTOS, Daniela. Empresas não Cumprem as Leis de Cotas. In: SINTHORESP. Releases. São Paulo, 2008. Disponível em: <http://www.sinthoresp.com.br/site/releases/empresas-nao-cumprem-a-lei-de-cotas> Acesso em: 10 fev. 2013. 
STAKE, Robert. Investigación con estudio de casos. Madrid: Morata, 1999.

VYGOTSKY, Lev Semenovich. A Formação Social da Mente. São Paulo: Martins Fontes, 1991.

VYGOTSKY, Lev Semenovich. Obras escogidas: fundamentos de defectología. Madrid: Visor, 1997. V. 5.

Vygotsky, Lev Semenovich. A construção do pensamento e da linguagem. São Paulo: Martins Fontes, 2001.

YIN, Robert. Applications of case study research. Thousand Oaks, CA: Sage, 1993.

Submetido para avaliação em 21 de março de 2015.

Aprovado para publicação em 13 de agosto de 2015.

Sandra Dutra Piovesan - Universidade Federal do Rio Grande do Sul, Porto Alegre, BR-RS. E-mail: sanpiovesan@ gmail.com

Rosana Wagner - Universidade Federal do Rio Grande do Sul, Porto Alegre, BR-RS. E-mail: rosanawagner@gmail. com

Roseclea Duarte Medina - Universidade Federal do Rio Grande do Sul, Porto Alegre, BR-RS. E-mail: roseclea.medina@gmail.com

Liliana Maria Passerino - Universidade Federal do Rio Grande do Sul, Porto Alegre, BR-RS. E-mail: Ipasserino@gmail. com 